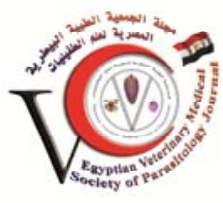

Original Article

\title{
Diagnosis and Follow up of Trypanosoma evansi infection by conventional and Real-time PCR assays
}

Tahani S Behour ${ }^{1}$, Shawki M Aboelhadid", Waheed MA Mousa ${ }^{3}$, Adel S Amin ${ }^{1}$

${ }^{1}$ Biotechnology Research Unit, Animal Reproduction Research Institute, Giza, Egypt

${ }^{2}$ Parasitology Department, Faculty of Veterinary Medicine, Beni Suef University, Egypt ${ }^{3}$ Parasitology Department, Faculty of Veterinary Medicine, Cairo University, Egypt

\begin{abstract}
:
This study was initiated to evaluate and compare two DNA based techniques (PCR and real-time PCR) with Direct Microscopic Examination for detection of Trypanosoma evansi. For this purpose, seventy three females' Swiss mice were divided into two groups. In group I, 21 mice were inoculated by $10^{4}$ trypanosomes. In group II, 42 mice were inoculated with $10^{2}$ parasites and 5 mice in each group were kept as non infected control. The pre-patent periods were followed daily by the three assays. Results showed higher sensitivities of PCR and real time PCR using both TBR1/2 and TeRoTat1.2 primer sets than direct microscopic examination in early determination of pre-patent periods as early as 24 hours post infection. Following up the course of infection by direct microscopic examination revealed three waves of parasitemia alternated with three waves of parasite disappearance from blood. The molecular techniques (PCR and real-time PCR) were able to clearly detect $T$. evansi in chronic stages of low parasitemia (waves of parasite disappearance) throughout the course of infection. By testing field samples, real time PCR was more reliable in detecting and quantifying very low parasitemia in clinical camels' blood samples than PCR. In conclusion, real time PCR can be considered more suitable for screening of newly introduced animals to exclude carriers and detect early infected animals for saving free herds.
\end{abstract}

Key words: Trypanosoma evansi, Acute, Chronic, Mice, PCR, Real-time PCR

\section{INTRODUCTION}

Trypanosoma evansi is one of the salivarian parasites which represent the most pathogenic trypanosome. It belongs to the genus Trypanosoma, subgenus Trypanozoon. T. evansi is considered the first discovered pathogenic trypanosome in the world. It was described by Griffith Evans, in 1880, in the blood of Indian horses and camels (Hoare, 1972). There is a hypothesis suggests that $T$. evansi originated from $T$. brucei by lacking the genes necessary for mitochondrial development, thus, loss the ability to develop and differentiate in insect vector. This change leads to non-cyclic mode of transmission for the parasite (Songa et al., 1990; Luckins, 1998). It is able to spread quickly by non-specific mechanical vectors present all over the world such as tabanids and stomoxys, and also by vampire bats in South America (Herrera et al., 2004; Otto et al., 2010). Trypanosoma evansi is enzootic in camels in Egypt and water buffaloes act as reservoir for camel infection (Hilali et al., 2004; Elhaig et al., 2013). The under estimation of the medical and economic impacts is resulted from its ability to diffuse silently via healthy carriers. Although, it is unapparent spreading parasite, it affects livestock productivity. The disease causes mortality, reduced animal production, reproduction performance, low carcass quality, decreased animal strength and high cost of treatment (Reid, 2002; Desquesnes et al., 2013).

Diagnosis of $T$. evansi infection relied on Sarataphan et al. (2007). Briefly, $50 \mu$ of each whole blood sample was lysed twice in $500 \mu$ of $0.1 \mathrm{M}$ ammonium chloride. After centrifugation, the sediment was resuspended in $50 \mu \mathrm{l}$ of $0.002 \%$ sodium dodecyl sulphate and $50 \mu \mathrm{l}$ of $5 \%$ chelex$100^{\circ}$ (Sigma) suspension in TE buffer (10 mM Tris- $\mathrm{HCl}, 0.1$ $\mathrm{mM}$ EDTA, $\mathrm{pH} 8.0$ ). The mixture was heated at $70^{\circ} \mathrm{C}$ for 8 minutes followed by heating to $100^{\circ} \mathrm{C}$ for 10 minutes. Finally, after centrifugation at $10,000 \mathrm{rpm}$ for $5 \mathrm{~min}$ at room temperature, the supernatant was stored at $-80^{\circ} \mathrm{C}$ for PCR analysis.

PCR and real-time PCR sensitivity for detection of $T$. evansi:

Detection of the parasite in the blood or tissue fluids of infected humans or animals. Parasitological techniques 
cannot always detect ongoing infections as the level of parasitemia is often low and fluctuating, particularly during the chronic stage of the disease which exhibits very low parasitemia (Nantulya, 1990). The other techniques like antigen $(\mathrm{Ag})$ and antibody $(\mathrm{Ab})$ dependable tests shows poor results. Consequently, their diagnostic sensitivity and specificity are unacceptable in situations where it is necessary to confirm that livestock are free from infection prior to introducing newly arrived animals or following control and eradication (Viljoen and Luckins, 2012). The molecular-based assays are described as the most powerful tools for the detection of $T$. evansi in several animals and vectors (Sukhumsirichartet et al., 2000). Molecular techniques enable researchers to identify and characterize the newly introduced $T$. evansi strains, detect mixed infection, study the disease epidemiology and study the interaction between vector and reservoir (Fernandez et al., 2009).

Therefore, we devote this study to compare and evaluate two different DNA detection based techniques (PCR and real-time PCR) for accurate and rapid detection of $T$. evansi on both experimental and field levels.

\section{MAterials AND MethodS}

\section{T. evansi strain, propagation and preservation:}

T. evansi isolate which isolated from naturally infected camel was obtained from Parasitology Department, Faculty of Veterinary Medicine, Cairo University. Parasite was expanded in white Swiss mice by I/P inoculation of infected mice blood. Preservation of the parasite in liquid nitrogen was carried out according to Shumei et al. (1996) till used in experimental infection and as a positive control in the molecular analysis.

\section{Experiment design}

Seventy three female Swiss mice of approximately $30 \mathrm{gm}$ of weight were used in the study. For First experiment, twenty six female mice were kept separately (group I). From that group, 21 mice were inoculated I/P by $10^{4}$ trypanosome (infective dose) according to (Sharma et al., 2012) and the other 5 mice were kept as non-infected control group. Forty seven mice were used for the second experiment (group II); 42 mice were inoculated I/P by $10^{2}$ trypanosome (infective dose) and the other 5 mice were kept as non-infected control group (Sharma et al., 2012). Three mice from each group were examined daily by preparing wet blood smears according to Brener (1962) from peripheral blood to detect the pre-patent period then sacrificed. Blood was collected on anti-coagulant for molecular examinations. By reaching parasitemia, all remaining mice were examined daily for assessment of parasitemic waves during the course of the infection.

\section{Field samples:}

Forty four blood samples were collected from apparently healthy camels from different locations in Giza and Nubariya, Egypt. Each Sample was tested microscopically for the presence of $T$. evansi and the rest of each sample was stored at $-20^{\circ} \mathrm{C}$ till used for molecular analysis.

\section{DNA extraction:}

DNA was extracted from positive control (T. evansi strain) and from each blood sample according to Sarataphan, et al. (2007). To determine the detection limit of the standard and real-time PCR assays and to establish a standard curves that could be used for quantification, 10 fold serial dilutions of known count of $T$. evansi $\left(10^{6}\right.$ trypanosomes) in tested non-infected camel blood. Dilutions were subjected to DNA extraction as described above then processed by conventional and SYBR Green real-time PCR as described below using TBR F - TBR R (Masiga et al., 1992) that amplifies a DNA fragment of 164 bp, and the TeRoTat920 F - TeRoTat1070 R (Konnai et al., 2009) primer pair that amplifies a DNA fragment of 151 bp.

\section{DNA amplification by conventional PCR assays:}

PCR analysis was done in standard PCR procedures. The PCR mixture of $25 \mu$ l contained $2 X$ PCR Dream Taq ${ }^{T M}$ Green PCR Master Mix (2x) (Fermentas, life science), 25 pmol of each primer, $2 \mu \mathrm{l}$ of DNA template and up to $25 \mu \mathrm{l}$ Nuclease free water were added. PCR using TBR F- (5' GAA TAT TAA ACA ATG CGC AG 3') and TBR R (5' CCA TTT ATT AGC TTT GTT GC $3^{\prime}$ ) were performed in a thermocycler (Nexus gradient Eppendorf, Germany) for initial denaturation at $95^{\circ} \mathrm{C}$ for 4 minutes, 30 cycles of denaturation at $95^{\circ} \mathrm{C}$ for $45 \mathrm{~s}$, annealing at $52^{\circ} \mathrm{C}$ for $45 \mathrm{~s}$, and extension at $72^{\circ} \mathrm{C}$ for $60 \mathrm{~s}$ and final extension at $72^{\circ} \mathrm{C}$ for 10 minutes. PCR using TeRoTat920 F- (5' CTG AAG AGG TTG GAA ATG GAG AAG 3') and TeRoTat1070 R (5' GTT TCG GTG GTT CTG TTG TTG TTA $3^{\prime}$ ) were performed in a thermocycler (eppendorf thermal Cycler, Germany) for initial denaturation at $95^{\circ} \mathrm{C}$ for 4 minutes, 35 cycles of denaturation at $95^{\circ} \mathrm{C}$ for $60 \mathrm{~s}$, annealing at $52^{\circ} \mathrm{C}$ for $60 \mathrm{~s}$, and extension at $72^{\circ} \mathrm{C}$ for $60 \mathrm{~s}$ and final extension at $72^{\circ} \mathrm{C}$ for 10 minutes. Amplicons were resolved on a $1.5 \%$ agarose gel stained with ethidium bromide (Sigma) and 
photographed under UV light (Sambrook and Russell, 2001). Positive control (T. evansi DNA) and negative control (reaction mixtures without DNA) were included in each PCR run. RoTaTat1.2 PCR product was sequenced at GATC Company (Germany) and compared to known published sequences to confirm that the correct DNA targets were being amplified.

\section{SYBR Green Real-Time PCR analysis:}

The Real-time quantitative PCR test was targeted at the $T$. evansi RoTat 1.2 VSG genes according to Konnai et al. (2009). Briefly, real-time PCR was performed in a final volume of $20 \mu \mathrm{l}$, using the $2 X$ Absolute MM QPCR SYBR Green Mix (Thermoscientific, AB gene, UK), $10 \mathrm{pmol}$ of each primer TBR and RoTat and $2 \mu \mathrm{l}$ of extracted DNA. Amplification was carried out in a RotorGene 6000 real time detection system (Corbett Research, Australia). The cycling profiles were: holding step at $95^{\circ} \mathrm{C}$ for 10 minutes, 40 cycles of $95^{\circ} \mathrm{C}$ for 10 seconds, $52^{\circ} \mathrm{C}$ for 20 seconds, $72^{\circ}$ $\mathrm{C}$ for 30 seconds for TBR primer set and $95^{\circ} \mathrm{C}$ for 10 seconds, $60^{\circ} \mathrm{C}$ for 20 seconds, $72^{\circ} \mathrm{C}$ for 30 seconds for TeRoTat primer set. A single fluorescence reading for each sample was taken at the extension step. Results were expressed by determination of the cycle threshold (Ct) which marked the cycle when the fluorescence of a given sample significantly exceeded the baseline signal. The melting step was set as default in the machine. Amplification curve analysis was performed in order to determine the amplicon cycle threshold (Ct). The melting temperature of the amplified products was determined by melting curve analysis to confirm the specificity of the amplified products with the standards and by agarose gel electrophoresis analysis.

\section{RESULTS}

Determination of Conventional and SYBR Green Realtime PCR sensitivity and detection limit of $T$. evansi:

PCR sensitivity was estimated using two primers sets TeRoTat1.2 and TBR1/2 with tenfold serial dilution of $10^{6}$ parasites/mL. By using TeRoTat1.2 primer set, the minimal detection limit was 10 parasites/ml blood. No extra bands were amplified except the $151 \mathrm{bp}$ target DNA band (Fig. 1A). By employing TBR1/2 primer set, the lowest detection limit was 0.0001 parasite/mL blood despite appearance of two extra non-specific bands in addition to 164 bp specifically amplified band (Fig. 1B). SYBR Green real-time PCR was carried out and standard curve were plotted for determination of assay sensitivity and detection limit. One hundredfold serial dilution of $10^{6}$ parasites/ml as dilution 1 for TBR1/2 was used instead of tenfold serial dilution for TeRoTat1.2. Assays analysis revealed $10^{-4}$ trypanosome $/ \mathrm{ml}$ for TBR1/2 as the lowest detection limit with melting temperature of $75^{\circ} \mathrm{C}$ detected by melt curve analysis (Fig. 2A). For TeRoTat1.2, 10 trypanosomes $/ \mathrm{ml}$ was estimated with melting temperature of $81.8^{\circ} \mathrm{C}$ as shown in (Fig. 2B). Results indicated that similar sensitivity in PCR and real time PCR with the two primer sets.

Following up the course of infection in experimentally infected mice:

The course of experimental infection was followed by daily microscopic examination of wet blood smears prepared from tail vein from day 1 post infection till day 7 PI. Different patterns were appeared in the infected groups according to the infective dose in mice. In experiment 1 (the group infected by $10^{4}$ trypanosomes), the pre-patent period was detected three days post infection and they reached the peak of parasitemia at the

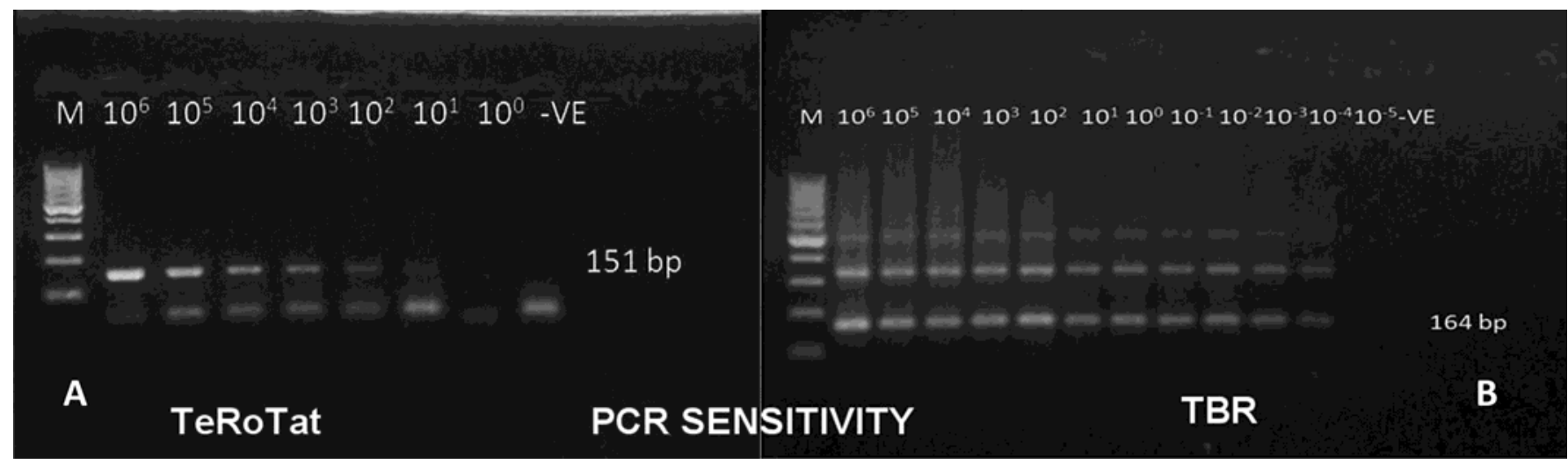

Figure 1: PCR detection limit by conventional PCR. Lane M: 100 bp molecular weight DNA marker. Lanes 1-12: different dilutions and -ve: negative control. 

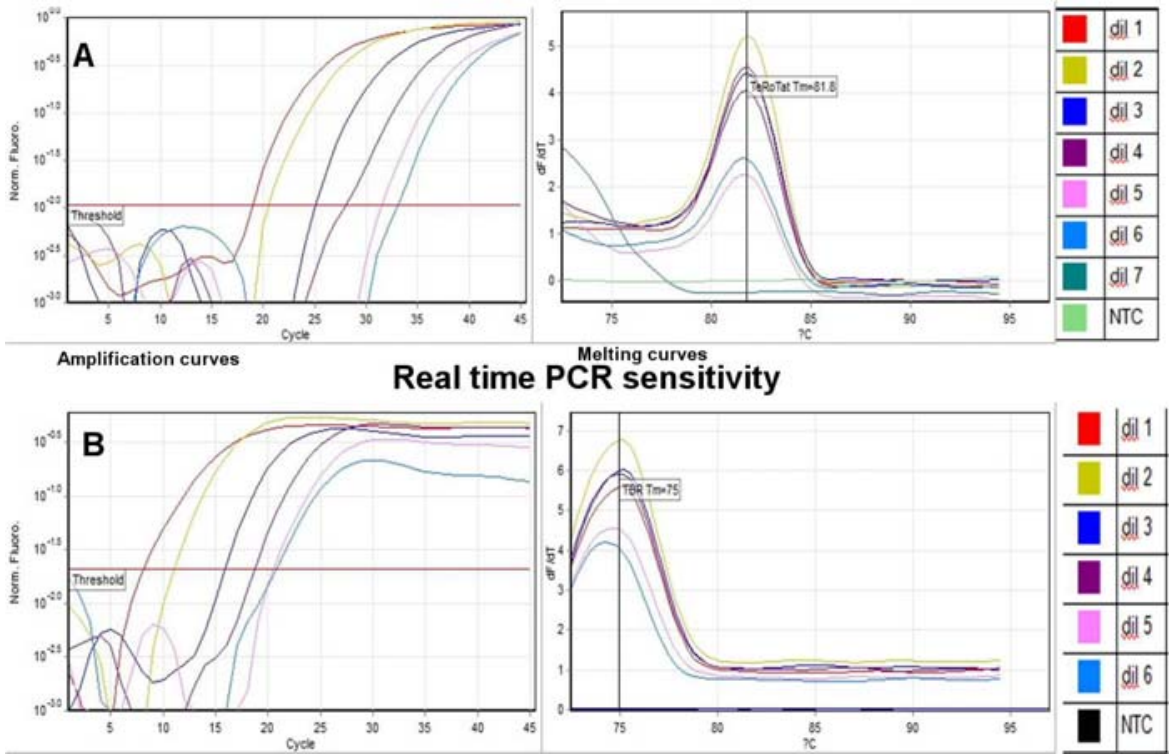

Figure 2: SYBR Green real time PCR sensitivity. (A) real time PCR detection limit using TeRoTat1.2 primer sets. Dill $1=10^{6}$, dil $2=10^{5}$, dil $3=10^{4}$, dil $4=10^{3}$, dil $5=10^{2}$ dil $6=10^{1}$, dil $7=10^{\circ}$ parasites and $\mathrm{NTC}=$ non template control. (B) detection limit using TBR primer sets. Dil $1=10^{6}$, dil $2=$ $10^{4}$, dil $3=10^{2}$, dil $4=10^{\circ}$, dil $5=10^{-2}$ dil $6=10^{-4}$ parasites. Amplification curves (relative fluorescence units are plotted against cycle number) and melting analysis (The melting temperatures are plotted against the fluorescence intensity).

seventh day post infection (Fig. 3 exp. 1) and all mice died within 7-9 DPI . In experiment 2 (group infected with $10^{2}$ parasites) as shown in (Fig. 3 exp. 2), there were many differences within the experiment. The pre-patent period was determined five days post infection. But by peaking parasitemia (ninth day $\mathrm{PI}$ ), three manners were observed, 6 mice showed persistent parasitemia and dead within the twelfth to thirty fourth days post infection G1. In contrast other sex mice showed disappearance of parasitemia by the fifteenth day $\mathrm{PI}$ and remained stable till the end of the experiment G2. Twelve mice of the group behaved the same manner in the course of the infection G3. This group showed three waves of parasitemia. The first was accomplished on the ninth day $\mathrm{PI}$, the second on the twenty second day $\mathrm{PI}$ and the last on the thirty fourth day PI. During this period, mice showed three time disappearance of the parasitemia at the fifteenth, twenty ninth and forty sixth days PI. Following up $T$. evansi infection using conventional PCR on mice blood was evaluated. The results were shown in Fig. 4 and Fig. 5 with the two different infective doses $10^{4}$ and $10^{2}$ parasites, respectively. It was found that the assay was able to detect $T$. evansi DNA from the first day post infection in both experiments. High detection sensitivity was obtained by using TBB1/2 primer sets (Fig. 4-A and Fig. 5-A) with convenient band intensity on the agarose gel throughout the course of infection. However by using RoTat1.2 primer sets, the intensity of the amplified bands was clearly observed increased gradually from the first day PI till the peak of parasitemia in experiments 1 and 2 as shown in Fig. 4(B) and Fig. 5(B), respectively. Following up T. evansi infection using real-time PCR on mice blood was also evaluated. The results were shown in Fig. 6 and Fig. 7 with the two different infective doses $10^{4}$ and $10^{2}$

\section{Experiment 1}

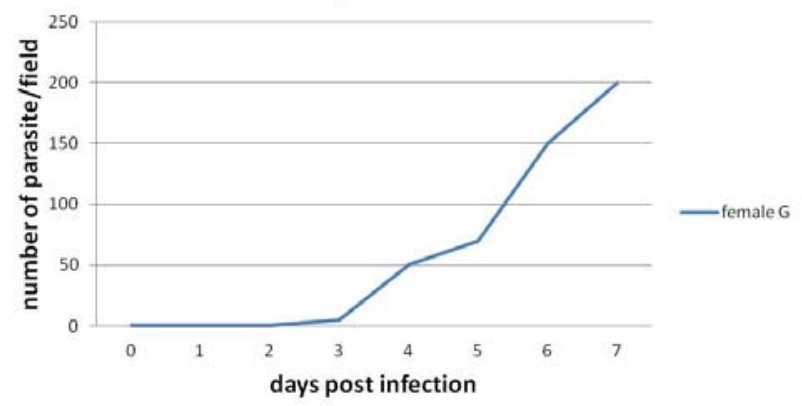

Experiment 2

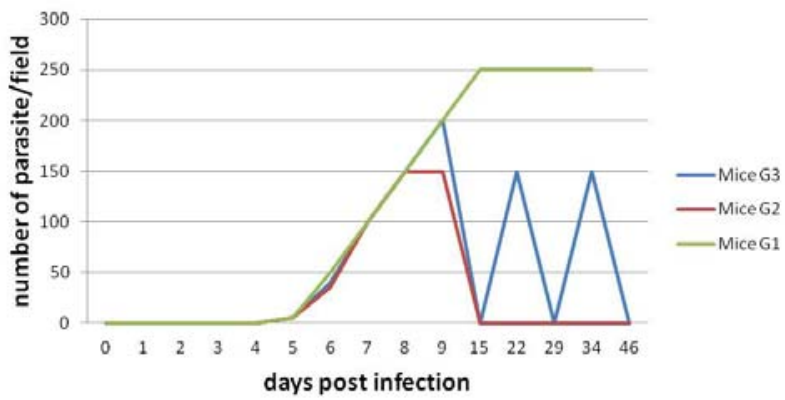

Figure 3: Following up course of infection. Charts showing the course of the parasitemia during the period of the experiment 1 $\left(10^{4}\right.$ infective dose) and experiment $2\left(10^{2}\right.$ infective dose) by direct microscopic examination. The days post infection is plotted against the approximately no. of parasite in the microscopic field. The plotted curves represent the different disease patterns obtained in mice during both experiments. 


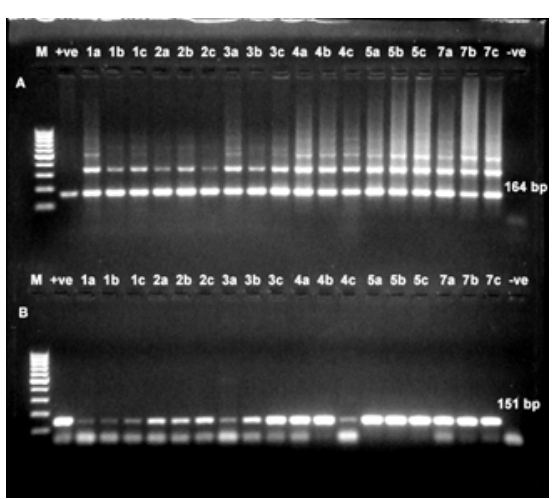

Figure 4: PCR on blood of mice injected by $10^{4}$ trypanosome. A: amplification using TBR1/2 primer sets. B: amplification using TeRoTat1.2 primer sets. M: 100bp molecular weight DNA marker, +ve: positive control, -ve: negative control, Numbers 1,2..: days post infection. Letters, a.b..: mice sacrificed at that day.

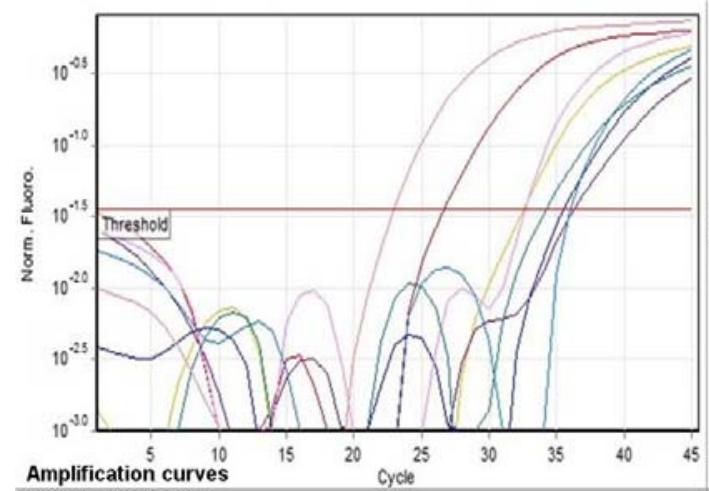

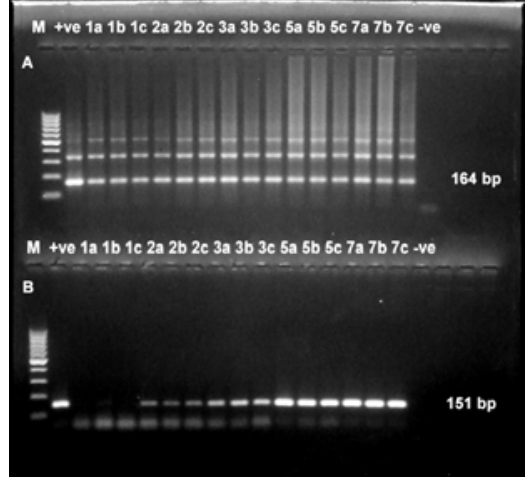

Figure 5: PCR on blood of mice injected by $10^{2}$ trypanosome. A: amplification using TBR1/2 primer sets. B: amplification using TeRoTat1.2 primer sets. M: $100 \mathrm{bp}$ molecular weight DNA marker, +ve: positive control, -ve: negative control, Numbers. 1,2..: days post infection. Letters, $a, b, \ldots:$ mice sacrificed at that day.

Figure 6: Amplification curves and melting curve analysis $(\mathrm{Tm})$ of experiment 1 for mice. Amplification curves: relative fluorescence units are plotted against cycle number. Melting curve analysis: The melting temperatures are plotted against the fluorescence intensity.
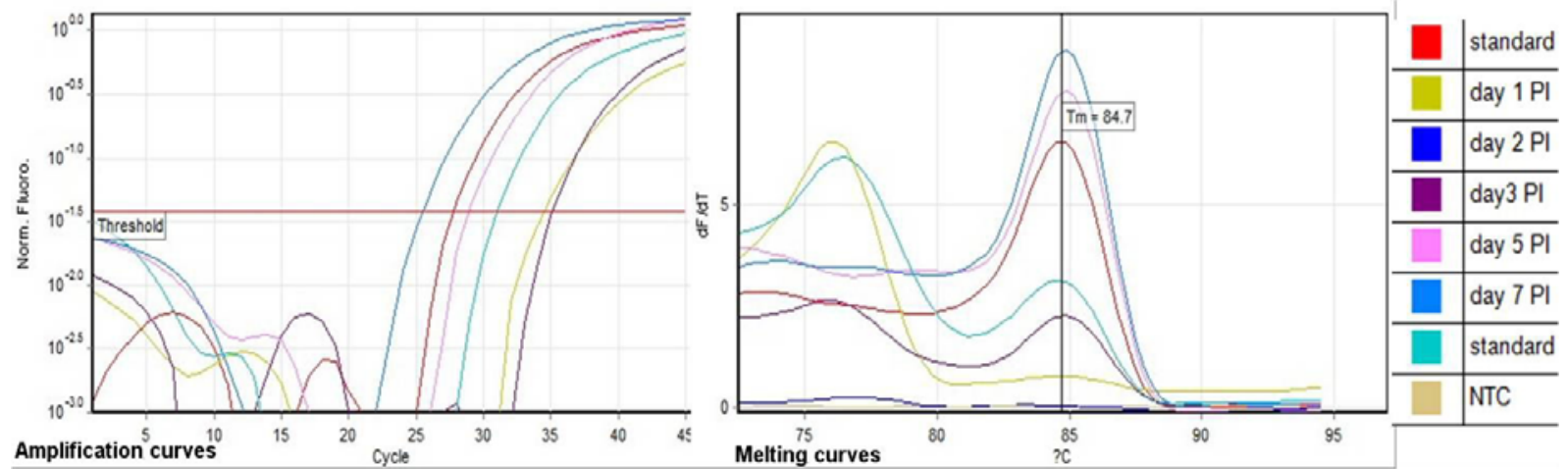

Figure 7: Amplification curves and melting curves analysis $(\mathrm{Tm})$ of experiment 2 for mice. Amplification curves: relative fluorescence units are plotted against cycle number. Melting curves analysis: The melting temperatures are plotted against the fluorescence intensity.

parasites respectively. Positive signals were obtained for $T$. evansi DNA in mice blood collected from the first to seventh day $\mathrm{PI}$ in both experiments. By using two standards dilutions as positive control, amplification was carried out using TeRoTat1.2 primer sets. Products with melting temperature ( $\mathrm{Tm}$ ) of 85 or under the melting curve area considered specific amplified DNA fragment for $T$. evansi corresponding to standard curves analysis as shown in Fig (6) for experiment 1 and Fig. (7) for experiment 2.
Detection of $T$. evansi in chronic phase (disappearance of parasite from blood):

Blood collected during the chronic phase was negative by microscopic examination of wet blood smear. By examination by PCR, $164 \mathrm{bp}$ and $151 \mathrm{bp}$ fragments were clearly detected for the two primers TBR $1 / 2$ and TeRoTat1.2, respectively as shown in Fig (8). 


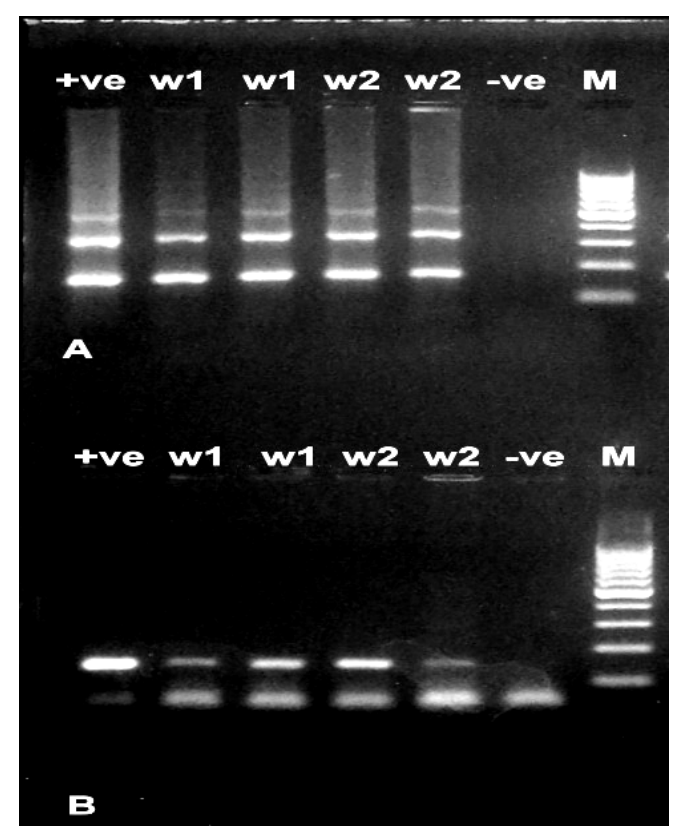

Figure 8: PCR on mice blood during the chronic phase. A: using TBR1/2 primer sets,

B: using TeRoTat1.2 primer sets, M: 100 bp molecular weight DNA marker and w1, w2: first and second waves of disappearance of parasite from blood.

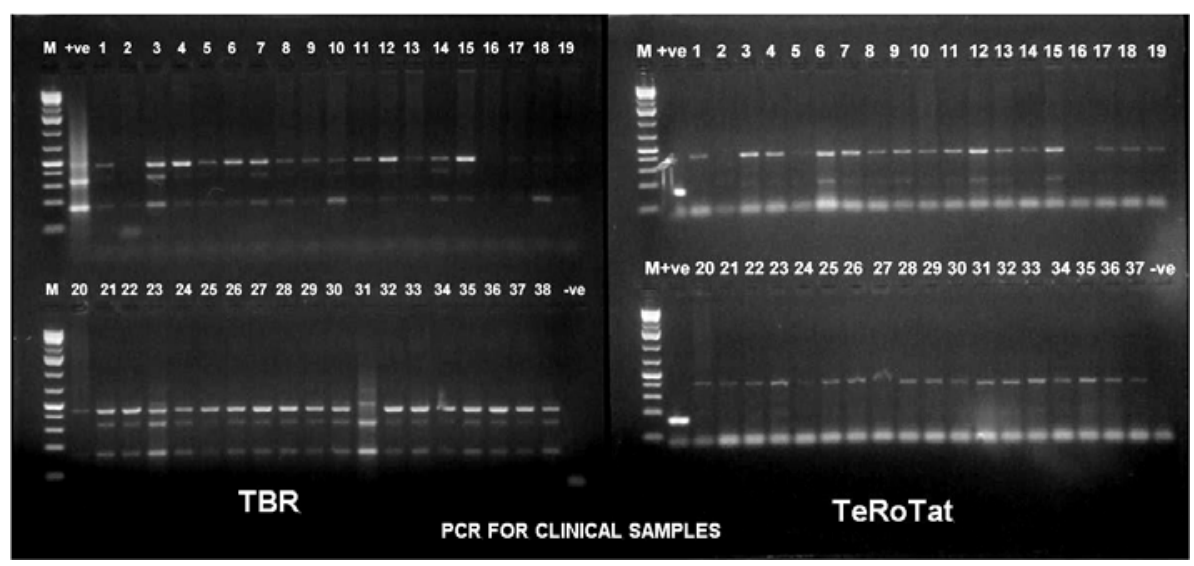

Figure 9: PCR of field blood samples with TBR1/2 (164 bp) and TeRoTat1.2 (151 bp) primers sets: M: 100 bp molecular weight DNA marker, +ve: positive control T. evansi DNA and -ve: negative control.
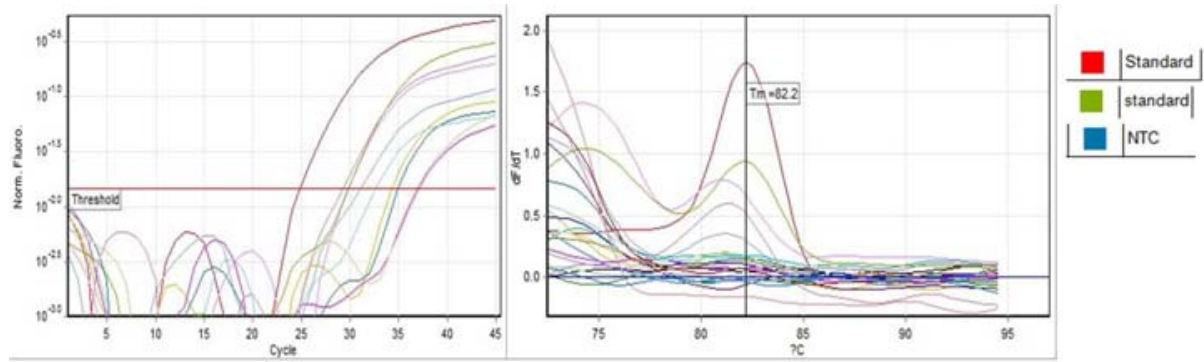

REAL TIME PCR FOR CLINICAL SAMPLES
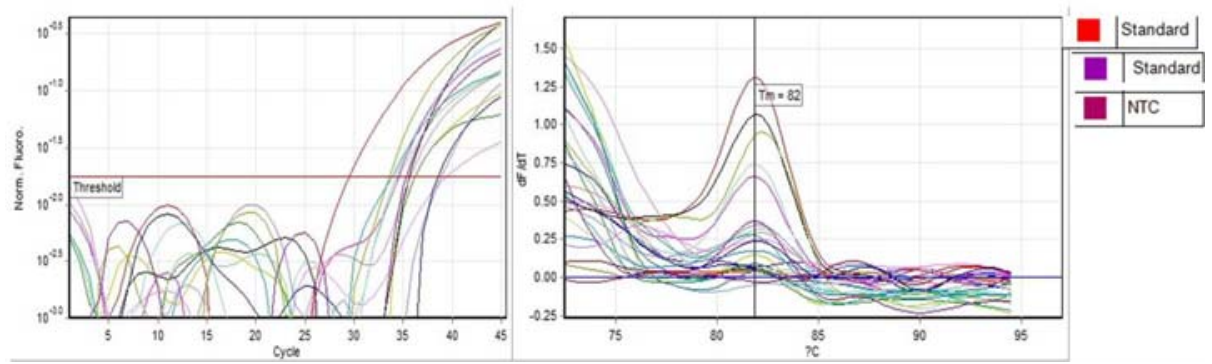

Figure 10: Amplification curves and melting curves analysis $(\mathrm{Tm})$ of field blood samples with TeRoTat1.2 primer sets 
Detection and Isolation of $T$. evansi from clinical samples: None of the all tested camel blood samples was positive for T. evansi by direct microscopic examination or isolated by mouse inoculation test. By conventional PCR as shown in Fig (9), all tested animals were positive for the presence of the parasite using TBR1/2 primer sets. However by using TeRoTat1.2 primer 32 animals were positive for T. evansi out of 44 animals. On the other hand, applying of SYBR Green real time PCR on field samples, 34 out of 44 samples were found positive for T. evansi DNA using TeRoTat1.2 primer set in combination with two dilutions standard used as positive control (Fig. 10).

BLAST search of GenBank for TeRoTat1.2 PCR product (151 bp) sequence revealed $100 \%$ identity with Trypanosoma evansi variable surface glycoprotein (VSG) sequence submitted by Sengupta et al. (2010) (accession number EF495337.1) in India, 100\% identity with Trypanosoma evansi clone RoTat1.2 variable surface glycoprotein directly submitted by Urakawa et al. (2001) (accession number AF317914.1) in Kenya and 99\% identity with Trypanosoma evansi RoTat 1.2 gene for variable surface glycoprotein submitted by Kumar et al. (2006) (accession number AB 259839.1) in India.

\section{Discussion}

Molecular techniques represent essential tools for detection of $T$. evansi infection. They become superior by their rapidity, accuracy and reliability in diagnosis (Desquesnes and Davila, 2002; Sengupta et al., 2010). Therefore, they become widely spread in detection of Surra all over the world. Recently, the development and spread of bioinformatics applied to genetic enable the design of many new primer sets for trypanosome detection. However, it is recommended to compare the newly designed primers with existing primer sets established as a gold standard (Pruvot et al., 2010). TBR1/2 primers were used to amplify a 164 bp highly repeated sequence $(10,000-20,000)$ of mini-chromosome satellite DNA (Masiga et al., 1992). It was known the gold standard since it was the first PCR primer set described with the highest sensitivity and largely used for detection of Trypanozoon DNA (Pruvot et al., 2010).

In the current study, TBR1/2 primer set was employed to evaluate the performance of TeRoTat1.2 primer set which amplify 151 bp DNA sequence. The later is targeting VSG gene which is the most reliable one for detection of $T$. evansi. It is expressed in early, middle and late stages of infection. So, it is recommended in early diagnosis and determination of carrier status (Sengupta et al., 2010).

Verification of sensitivity of the primers revealed 0.0001 trypanosome/ml blood for TBR1/2 using conventional PCR assay (Fig. 1). This finding elucidated the highly positive results with considerable band intensity obtained from TBR1/2 PCR throughout the course of the experiments. The sensitivity was higher than obtained by Pruvot et al. (2010) and Fernandez et al. (2009) which were 0.1 parasite $/ \mathrm{mL}$ and 0.001 parasite $/ \mathrm{mL}$, respectively. On the other hand, the sensitivity of TeRoTat1.2 PCR was 10 parasites/ml blood (Fig. 1). Low band intensity was correlated with parasite number during the early stages of infection in mice. Bands comparison with that obtained by TBR1/2 explained the sensitivity difference between the two primers. In real-time PCR assay, sensitivities of TBR1/2 and TeRoTat1.2 primers were verified. After analysis of generated standard curve, the detection limits for TBR1/2 and TeRoTat1.2 primers showed no difference with obtained by conventional PCR (Fig. 2). Konnai et al. (2009) established quantitative real-time PCR assay with SYBR Green for detection of $T$. evansi for TeRoTat1.2 gene. They reached $10^{2}$ parasites $/ \mathrm{mL}$ blood detection limit. Authors' sensitivity level similar to the previous report for the detection of $T$. brucei (Becker et al., 2004) but this study achieved higher sensitivity of 10 parasites $/ \mathrm{mL}$ blood for the same target. However, Taylor et al. (2008) determined minimum detection limit as 0.36 genomic equivalent $/ \mathrm{mL}$ blood using TaqMan primer and probe targeting the internal transcribed spacer 1 (ITS-1) region of rRNA for $T$. evansi. Sharma et al. (2012) obtained nearly similar results with the same gene target which were 6.12 and 0.33 genomic $\mathrm{DNA} / \mathrm{mL}$ for purified trypanosomal DNA and whole blood DNA, respectively. In $T$. evansi protozoan infection, evaluation of parasitemia level is important for monitoring the health status of the hosts, determination of disease stage and risk of transmission between animals in the field. Experimental infection of $T$. evansi was done in mice with two different doses in order to follow up the disease and determine the more suitable technique for early detection of the parasite. Infection of mice with $10^{4}$ trypanosomes in experiment 1 and with $10^{2}$ trypanosomes in experiment 2 showed variable disease patterns (Fig 3). The variation was referred to the dose of inoculums of experimental animals. Microscopic examination of wet blood smears showed no difference in the pre-patent periods between mice group in experiment $1\left(10^{4}\right.$ infective dose) which was 3 days post infection. The rest of mice 
were died by the ninth day post infection from acute parasitemia. In experiment $2\left(10^{2}\right.$ ID), the pre-patent period was delayed two days than the exp. 1 as a result of decreased inoculums dose. Nearly the same results were obtained by Sharma et al. (2012) after experimental infection of $T$. evansi in mice and detected the parasite at 3 days and 4.5 days after inoculation of $10^{4}$ and $10^{2}$ parasites, respectively. The different patterns of infection released from infection by $10^{2}$ parasites elucidated the immune response of the animals. The group showed consistent parasitemia until death (Fig. 3G1) was reflecting its depressed immune status and represented the acute form of the disease. Where the group revealed persistent chronic undetectable infection (Fig. 3G2), reflected the immune resistance against infection and represented the carrier stage. The group showed fluctuating parasitemia throughout the course of infection (Fig. 3G3), was the mirror of antigenic variation of $T$. evansi and evasion of host immune response (Maudlin et al., 2004). This mechanism resulted from parasite ability to periodically switch its major variant surface glycoprotein producing relapse of parasitemias (Herrera et al., 2004). Comparing results obtained by conventional parasitological test (CPT) and that obtained by molecular techniques in experimental infection in mice, conventional PCR with TBR1/2 and TeRoTat1.2 primer sets was able to detect the parasite as early as one day post infection in mice (Fig 4\&5). However, microscopic examination detected parasite 3 days $\mathrm{PI}$ in exp. 1 and 5 days $\mathrm{PI}$ in exp. 2. All tests were able to detect parasite with peaking of parasitemia. The same results were achieved by Sengupta et al. (2010) using DTRYF/R primers after the experimental infection in rats and by Ashour et al. (2013) using TBR $1 / 2$ in mice. However, Fernandez et al. (2009) determined the prepatency $12 \mathrm{~h}$ post-infection in mice by TBR1/2 and one day PI by ITS1 primers sets. Striking difference in intensity of the bands amplified by TeRoTat1.2 primer sets from day one till appearance of consistent parasitemia is related to DNA concentration of the parasite in blood of each mice group sacrificed that day. Gonzalez et al. (2006) and Fernandez et al. (2009) confirmed that the proportion of DNA of the parasite relative to the total DNA in blood sample. Therefore, they recommended usage of at least $100 \mathrm{ng}$ DNA in the sample when parasitemia is lower than $10^{3}$ parasite/mL to ensure the detection of parasite by PCR assay. In TBR1/2 PCR, the intensity of the amplified bands showed little or no difference through the course of infection. This is related to the highly repeated sequence of amplified target which overcome low parasitic DNA concentration in the sample. In the current study, SYBR
Green real-time PCR assay was employed by TeRoTat1.2 primer sets as described by Konnai et al. (2009). Results provided pre-patency periods of one day post infection with $10^{2}$ and $10^{4}$ trypanosome in both experiments in mice as obtained by conventional PCR (Fig. 6\&7). The results were confirmed by melting curves analysis in spite of agarose gel electrophoresis so much time was saved and post PCR carry over was overcome. Taylor et al. (2008) detected parasite 6 days $\mathrm{PI}$ in rats injected with $10^{4}$ trypanosomes by ITS-1 TaqMan real time PCR. However Sharma et al. (2010) detected the parasite 1.5 days PI in mice infected with $10^{4}$ parasites and 3 days $\mathrm{PI}$ with $10^{2}$ parasites by the same assay. Differences between obtained results and that previously mentioned might be referred to different real-time chemistries, profiles and different target sequences used in the techniques.

Moreover, in this study PCR based techniques were able to detect clearly $T$. evansi during the chronic phase of the disease in mice where CPT could not (Fig 8). This limited sensitivity and false negative results of CPT are resulted from fluctuating parasitemia and presence of parasite with low number (Nantulya, 1990). Obtained results were supported by Ashour et al. (2013) in experimental mice infection and Ramirez-Iglesias et al. (2011) using rabbit as experimental model. Variations of the results obtained by previous authors and current study supposed to be due to diversity of trypanosome strains, different PCR conditions, different primers sets used in the studies and DNA extraction methods as mentioned by Fernandez et al. (2009). In this work, Chelex resin was used for DNA extraction from blood samples. The method provided high DNA yield with convenient purity, less laborious and overcome the toxic effect and risk of sample carry over with foreign DNA which occurs by using organic extractions (Herrera et al., 2005).

Survival duration in current study was recorded 7-9 days in the first experiment in mice. In experiment II, survival duration was stretching 12-46 days. Different survival durations were recorded by many researchers; Shama et al. (2012) recorded survival duration of mice inoculated with $10^{4}$ trypomastigotes of 7 days and 10-14 days for mice inoculated by $10^{2}$ trypomastigotes, Carmona et al. (2006) recorded survival durations 12-24 days in mice inoculated with 1 trypomastigote/gm body weight. Mekata et al. (2012) inoculated mice with $10^{3}$ trypomastigotes and obtain survival duration of 9- 20 days. Shams El-Din (2012) obtained 11.2 days as the mean survival time of mice inoculated with $4.5 \times 10^{5}$ with overall 
mortality within 30 days. Mekata et al. (2013) recorded 19.8 days as a means of survival days of $60 \%$ from mice inoculated with $2.0 \times 10^{3}$ purified parasites. The other $40 \%$ of mice were survived till 30 days and authors didn't show whether mice were sacrificed or died. Tejero et al. (2008) inoculated mice with 1 trypomastigote/g of body weight and mice revealed a distinctive undulatory-like parasitemic pattern that resembles waves for 39 days. Moreover, Araque (1985) found in his study that two mice strains were able to overcome the acute phase with survival times up to 60 days. The variation in survival time of mice inoculated with $T$. evansi may be attributed to the strain virulence, host susceptibility, inoculated dose and environmental factors. In this study environmental temperature was critical factor for mice survival as the experiments were carried out in December.

Application of CPT and PCR based techniques on field blood samples showed variable results among the assays. Direct microscopic examination by wet blood smear revealed negative results for all tested samples. These results might be influenced by samples preservation and transportation until reaching the laboratory for examination. At this situation, it considered one of the drawbacks of using CPT in diagnosis. The concept was supported by Holland et al. (2001) who reported that trypanosomes in samples from animals with high $\left(>10^{4}\right.$ trypanosomes $/ \mathrm{mL}$ of blood) and low parasitaemia (250 trypanosomes $/ \mathrm{mL}$ of blood) could not be detected beyond 8 and 3 hours after storage at $4^{\circ} \mathrm{C}$ and $27^{\circ} \mathrm{C}$, respectively to maintain viability of trypanosome in blood. So T. evansi was not detected mostly on blood smears derived from field samples. In this study, examination the same samples by conventional PCR with TBR1/2 primers showed positive results for all samples While TeRoTat1.2 PCR showed 32 positive samples out of 44 (Fig 9). The decreased number of positive samples by PCR targeting RoTat1.2 compared with that obtained by TBR1/2 was attributed to several factors such as, number of copies of the target sequence on the genome, level of parasitemia, concentration of parasitic DNA and existence of non-RoTat1.2 VSG T. evansi variant that was previously reported in Kenya (Sengupta et al., 2010). Similar results were obtained by Elhaig et al. (2013). They reported that TBR primers showed higher sensitivity and specificity than five other primer sets for the detection of $T$. evansi and were able to detect parasitemia below one parasite per $\mathrm{ml}$ of blood.

On the other hand, Quantitative Real-time PCR on field samples achieved more convenient results than obtained by conventional PCR using RoTat1.2 primer sets. Thirty four samples were positive out of 44 samples (Fig 10). Results showed that the $T$. evansi positive animals had parasitemia levels ranging from 1 to 404 parasites per $\mathrm{mL}$ blood confirmed by melting curve analysis although standard curve could not be generated by $<10$ parasites/ $\mathrm{mL}$. Konnai et al. (2009) could not establish the putative parasitemia levels in some water buffalos as the values were outside the linear range of the standard curve generated in their assay. Their assay detection limit was $10^{2}$ parasites per $\mathrm{mL}$. Noteworthy, Eberhardt et al. (2014) reported no differences between smear microscopy and real-time PCR assays used to detect the presence of $T$. evansi in capybaras from Argentina.

In conclusion, the striking variations obtained by comparing the parasitological and molecular PCR based techniques are the guide for choice. Results provided by conventional and real time PCR assays were exciting and interesting. They provided high sensitivity and accuracy within minute time. No risk from sample handling, preservation and transportation in addition to small sample quantity required for applying the tests. Fortunately, with application of real time PCR, it provided more convenient detection in field samples than conventional PCR. It overcame the poor precision of amplified bands on agarose gel. Moreover, it succeeded to accurately assess the low parasitemia levels in the tested animals. Thus, it can be considered more suitable for this purpose in addition to use for screening of newly introduced animals to exclude carriers and detect early infected animals for saving free herds.

\section{REFERENCES}

Araque, W.H. (1985): Trypanosoma venezuelense en ratones: susceptibilidad a la infección y alteraciones de larespuesta inmune. Trabajo Especial de Grado de Maestría. Intituto Venezolano de Investigaciones Científicas. Caracas.

Ashour, A., Abou El-Naga, T., Barghash, S. and Salama, M., (2013): Trypanosoma evansi: Detection of Trypanosoma evansi DNA in naturally and experimentally infected animals using TBR1 and TBR2 primers. Experimental Parasitology. 134: 109-114.

Becker, S., Franco, J.R., Simarro, P.P., Stich, A., Abel, P.M. and Steverding, D., (2004): Real-time PCR for detection of Trypanosoma brucei in human blood samples. Diagn. Microbiol. Infect. Dis. 50: 193-199.

Brener, Z., (1962): Therapeutic activity and criterion of cure on mice experimentally infected with Trypanosoma cruzi. Rev. Inst. Med. Trop. Sao Paulo 4, 389-396. 
Carmona, T.M.P., Garrizzo J., Roschman-González A., Tejero F., Escalante A. and Aso P.M. (2006): Susceptibility of different mouse strains to experimental infection with a Venezuelan isolate of Trypanosoma evansi. J. Protozool. Res. 16, 1-8

Desquesnes, M., Holzmuller, P. Lai, D. Dargantes, A. Lun, Z. and Jittaplapong, S. (2013): Trypanosoma evansi and Surra: A Review and Perspectives on Origin, History, Distribution, Taxonomy, Morphology, Hosts, and Pathogenic Effects. BioMed Research International, Article ID 194176, 22 pages.

Desquesnes, M. and Davila, A.M.R. (2002): Applications of PCR-based tools for detection and identification of animal trypanosomes: a review and perspectives. Vet. Parasitol. 109: 213-231.

Eberhardt, A.T. Monje, L.D. Zurvera, D.A. and Beldomenico, P.M. (2014): Detection of Trypanosoma evansi infection in wild capybaras from Argentina using smear microscopy and real-time PCR assays. Veterinary Parasitology. 202 (3/4): 226-233.

Elhaig, M., Youssef, A., El-Gayar A. (2013): Molecular and parasitological detection of Trypanosoma evansi in Camels in Ismailia, Egypt. Veterinary Parasitology. 198: 214-218.

Fernandez, D., Gonzalez-Baradat, B., Eleizalde, M., Gonzalez-Marcano, E., Perrone, T. and Mendoza, M. (2009): Trypanosoma evansi: A comparison of PCR and parasitological diagnostic tests in experimentally infected mice. Exp. Parasitol., 121(1): 1-7.

González, E., González-Baradat, B., González, R., Linares, N., Mijares, A., Perrone, T., Mendoza, M. (2006): Desarrollo de la técnica de reacción en cadena de la polimerasa para el diagnóstico de la trypanosomosis animal causada por Trypanosoma evansi. Agronomia Trop., 56: 496-500.

Herrera, H.M., Davila, A.M.R., Norek, A., Abreu, U.G., Souza, S.S., D'Andrea, P.S. and Jansen, A.M. (2004): Enzotiology of Trypanosoma evansi in Pantanal. Brazil. Vet. Parasitol., 125: 263-275.

Herrera, H.M., Norek, A., Freitas, T.P., Rademaker, V., Fernandes, O. and Jansen, A.M. (2005): Domestic and wild mammals infection by Trypanosoma evansi in a pristine area of the Brazilian Pantanal region. Parasitol. Res., 96: 121-126.

Hilali M., Abdel-Gawad A., Nassar A., Abdel-Wahab A., Magnusb E. and Büscher P. (2004): Evaluation of the card agglutination test (CATT/T. evansi) for detection of Trypanosoma evansi infection in water buffaloes (Bubalus bubalis) in Egypt. Veterinary Parasitology, 121: 45-51.

Hoare, C.A. (1972): The Trypanosomes of Mammals. A Zoological Monograph. Blackwell Scientific Publications, Oxford, U.K, P.749.

Holland, W.G., Claes, F., My, L.N., Thanh, N.G., Tam, P.T., Verloo, D., et al. (2001): A comparative evaluation of parasitological tests and a PCR for Trypanosoma evansi diagnosis in experimentally infected water buffaloes. Vet. Parasitol., 97 (1): 23-33.

Konnai, S., Mekata, H., Mingala, C.N., Abes, N.S.,
Gutierrez, C.A., Herrera, J.R., et al. (2009): Development and application of a quantitative real-time PCR for the diagnosis of Surra in water buffaloes. Infect. Genet. Evol., 9: 449-452.

Kumar, R., Kumar, S. and Dwivedi, S.K. (2006): Amplification of RoTat 1.2 gene fragment of Trypanosoma evansi (Indian strain) by PCR. Direct Submission National Research Centre on Equines, Sirsa Road, Hisar, Haryana; Sirsa Road, Hisar, Haryana, 125001, India.

Luckins, A.G., (1988): Trypanosoma evansi in Asia. Parasitol. Today, 4(5): 137-142.

Masiga, D.K., Smyth, A.J., Hayes, P., Bromidge, T.J. and Gibson, W.C. (1992): Sensitive detection of trypanosomes in tsetse flies by DNA amplification. Int. J. Parasitol., 22: 909-918.

Maudlin, I., Holmes, P.H. and Miles, M.A. (2004): The Trypanosomiasis. CABI Publishing CAB International, Oxfordshire, UK, Pp. 25-30: 283-331.

Mekata H., S. Konnai, C.N. Mingala, N.S. Abes, C.A. Gutierrez, A.P. Dargantes, et al. (2012): Kinetics of regulatory dendritic cells in inflammatory responses during Trypanosoma evansi infection. Parasite Immunology, 34: 318-329.

Mekata H., S. Konnai, C.N. Mingala, N.S. Abes, C.A. Gutierrez, A.P. Dargantes, et al. (2013): Isolation, cloning, and pathologic analysis of Trypanosoma evansi field isolates. Parasitol Res 112:1513-1521.

Nantulya, V.M. (1990): Trypanosomiasis in domestic animals: the problems of diagnosis. Rev. Sci. Tech. Off. Int. Epizoot., 9: 357-367.

Otto, M.A., Da Silva, A.S., Gressler, L.T., Farret, M.H., Tavares KC. and Zanette R.A. (2010): Susceptibility of Trypanosoma evansi to human blood and plasma in infected mice. Vet Parasitol., 168(1-2): 1-4.

Pruvot, M., Kamyingkird, K., Desquesnes, M., Sarataphan, N. and Jittapalapong, S. (2010): A comparison of six primer sets for detection of Trypanosoma evansi by polymerase chain reaction in rodents and Thai livestock. Vet. Parasitol., 171: 185-193.

Ramírez-Iglesias, J. Eleizalde , M. Gómez-Piñeres, E. and Mendoza M. (2011): Trypanosoma evansi: A comparative study of four diagnostic techniques for trypanosomosis using rabbit as an experimental model. Experimental Parasitology, 128: 91-96.

Reid, S.A. (2002): Trypanosoma evansi control and containment in Australasia. Trends Parasitol., 18(5): 219224.

Sambrook, J. and Russell, D.W. (2001): Molecular Cloning: A laboratory Manual. Cold Spring Harbor Laboratory Press, Cold Spring Harbor, NY.

Sarataphan, N., Unjit, K., Vongpakorn M. And Indrakamhaeng, P. (2007): Real-Time PCR for detection of Trypanosoma evansi in blood samples using SYBR Green I fluorescent dye. In: Proceeding Developing Methodologies for the Use of Polymerase Chain Reaction in the Diagnosis and Monitoring of Trypanosomosis, IAEA-TECDOC-1559, Pp. 93-102. 
Sengupta, P.P., Balumahendirana, M., Suryanaryanab, W., Raghaven-dra, A.G., Shomea, B.R., Gajendragada, M.R. and Prabhudas, K. (2010): PCR-based diagnosis of surra-targeting VSG gene: experimental studies in small laboratory rodents and buffalo. Vet. Parasitol., 171: 22-31. Shams El-Din A.S. (2012): Effect of Human Immunogloblins on Experimental Murine Trypanosomiasis Caused by Trypanosoma evansi. PUJ; 5(1): 11-18.

Sharma A.K., Pallesen L.J., Spang R.J. and Walden W.E., (2010): Cytosolic iron-sulfur cluster assembly (CIA) system: factors, mechanism, and relevance to cellular iron regulation. J. Biol. Chem., 285(35): 26745-26751.

Sharma P, Juyal PD, Singla LD, Chachra D and Pawar H., (2012): Comparative evaluation of real time PCR assay with conventional parasitological techniques for diagnosis of Trypanosoma evansi in cattle and buffaloes. Vet. Parasitol., 190 (3-4): 375-82.

Shumei, Z. Yongzhi, Z. Yunfei ,W. and Renjian, Z., (1996): Comparative study on different methods of preserving Trypanosoma evansi by liquid nitrogen cryofreezing. Chinese Journal of Veterinary Parasitology, 1996-04.

Songa, E., Paindavoine, P. and Wittouck E. (1990): Evidence for kinetoplast and nuclear DNA homogeneity in Trypanosoma evansi isolates. Molecular and Biochemical Parasitology, 43: 167-179.
Sukhumsirichart, W., Khuchareonaworn S., Sarataphan, N. Viseshakul, N. and Chansiri K., (2000): Application of PCR-based assay for diagnosis of Trypanosoma evansi in different animals and vectors. J. Trop. Med. Parasitol., 23: 1-6.

Taylor, T.K., Boyle, D.B. and Bingham, J., (2008): Development of a TaqMan PCR assay for the detection of Trypanosoma evansi, the agent of surra. Vet. Parasitol., 153(3-4): 255-264.

Tejero, F., Roschman-González, A., Perrone-Carmona, T.M. and Aso, P.M. (2008): Trypanosoma evansi: A quantitative approach to the understanding of the morphometry-hematology relationship throughout experimental murine infections. J. Protozool. Res. 18, 3447.

Urakawa, T., Verloo, D., Moens, L., Büscher, P. and Majiwa, P.A.O., (2001): Trypanosoma evansi: cloning and expression in Spodoptera fugiperda insect cells of the diagnostic antigen RoTat 1.2. Experimental Parasitology, 99: 181-189.

Viljoen, G.J. and Luckins, A.G., (2012): The role of nuclear technologies in the diagnosis and control of livestock diseases--a review. Trop. Anim. Health Prod., 44(7):134166. 